Timo Sipiläinen ja Timo Kuosmanen

MTT Taloustutkimus, Luutnantintie 13,00410 Helsinki, etunimi.sukunimi@mtt.fi

\title{
Tuottavuuserot pohjoismaiden maitotiloilla
}

\section{Tiivistelmä}

Tuotanto-olosuhteet poikkeavat huomattavasti Tanskan, Ruotsin ja Suomen välillä. Tuotantoolosuhteista ja erilaisesta historiallisesta kehityksestä johtuen eri maiden ja alueiden maatilat poikkeavan toisistaan myös tuottavuuden eli panos-tuotos -suhteen tasoltaan. Tuottavuuden taso on puolestaan tärkeä tekijä tuotannon kilpailukyvyn kannalta, kun tuote on melko homogeeninen. Alkutuotannon kilpailukykyisyys on tärkeä myös jalostavan teollisuuden näkökulmasta, koska esimerkiksi raakamaitoa ei kannata kuljettaa jalostettavaksi pitkiä matkoja. Tuotannon kilpailukykyä voidaan pitää yllä myös tukien avulla. Tuen tarvetta voidaan puolestaan perustella todellisten, viljelijöistä riippumattomista tekijöistä johtuvien tuottavuuserojen avulla. Tässä tutkimuksessa tuottavuuseroa arvioidaan nk. meta-rintamatekniikoita käyttäen, jossa alueiden välinen tuottavuusero jaotellaan alueiden tuottavuuden tason eroiksi sekä alueiden sisäisiksi tuottavuus-/tehokkuuseroiksi. Käytännössä näiden määrittäminen edellyttää kaikkien tilojen yhteisen tehokkuusrintaman sekä alueellisten tehokkuusrintamien määrittämistä.

Tämän tutkimuksen tavoitteena on tutkia eri menetelmiä käyttäen, onko maidontuotannossa tilatason tuottavuuseroja Suomen, Ruotsin ja Tanskan välillä. Tutkimuksessa sovelletaan eri menetelmiä, mm. stokastista ei-parametrista estimointia. Sen antamia tuloksia verrataan stokastisen parametrisen ja ei-stokastisen ei-parametrisen DEA -menetelmän tuottamiin tuloksiin.

Tutkimusaineisto koostuu EU:n ylläpitämän FADN -aineiston maitotiloista vuodelta 2003. Erikoistuneiden maitotilojen oletetaan tuottavan yhtä tuotosta, joka koostuu pääasiassa maidosta ja maidontuotannon sivutuotteista. Panoksina ovat perinteiset tuotantopanokset: lannoitteet, ostorehut, työ, muut muuttuvat panokset sekä koneet ja rakennukset.

Tulosten mukaan eri menetelmät tuottavat samankaltaisen tuottavuuseron eri maiden välille. Tuottavuuserot ovat merkittäviä. Tanskan tilat ovat kaikilla menetelmillä tuottavuudeltaan parhaita ja Suomen heikoimpia eron ollessa 20 - 30 prosenttia menetelmästä riippuen. Tästä huolimatta suomalaiset tilat ovat suomalaisiin tiloihin verrattuna keskimäärin jokseenkin yhtä tehokkaita kuin tanskalaiset tanskalaisiin verrattuna. Ruotsalaistilojen keskimääräinen tekninen tehottomuus niiden omaan tuotantorintamaan verrattuna on suomalaistiloja suurempi.

Avainsanat: tuottavuus, tekninen tehokkuus, meta-tuotantorintama 


\section{Johdanto}

Tuotanto-olosuhteet poikkeavat huomattavasti Tanskan, Ruotsin ja Suomen välillä. Tuotantoolosuhteista ja erilaisesta historiallisesta kehityksestä johtuen eri maiden ja alueiden maatilojen voidaan olettaa poikkeavan toisistaan myös tuottavuuden eli panos-tuotos -suhteen tasoltaan. Tuottavuuden taso on puolestaan tärkeä tekijä tuotannon kilpailukyvyn kannalta, jos tuote on melko homogeeninen ja maiden kustannustasot ovat lähellä toisiaan. Alkutuotannon kilpailukykyisyys on tärkeä tekijä myös jalostavan teollisuuden näkökulmasta, koska esimerkiksi raakamaitoa ei kannata kuljettaa jalostettavaksi pitkiä matkoja. Tuotannon kilpailukykyisyyttä voidaan pitää yllä heikoilla tuotantoalueilla myös tukien avulla. Tuen tarvetta voidaan puolestaan perustella todellisten, viljelijöistä riippumattomista tekijöistä, kuten ilmastosta tai maaperästä johtuvien tuottavuuserojen avulla. Tässä tutkimuksessa tuottavuuseroa arvioidaan nk. meta-rintamatekniikkaa käyttäen, jossa maiden välinen tuottavuusero jaotellaan alueiden tuottavuuden tason eroiksi sekä alueiden sisäisiksi tuottavuus-/tehokkuuseroiksi. Käytännössä näiden määrittäminen edellyttää kaikkien tilojen yhteisen tehokkuusrintaman sekä alueellisten tehokkuusrintamien määrittämistä.

Tämän tutkimuksen tavoitteena on tutkia eri menetelmiä käyttäen, onko maidontuotannossa tilatason tuottavuuseroja Suomen, Ruotsin ja Tanskan välillä ja kuinka suuria nämä tuottavuuserot ovat. Perusmenetelmänä käytetään edellä mainittua meta-rintamalähestymistapaa, jossa tuottavuusero voidaan jaotella alueellisten tuotantorintamien eroiksi ja teknisen tehokkuuden alueellisiksi eroiksi. Tutkimuksessa sovelletaan kolmea eri menetelmää maittaisen teknisen tehokkuuden määrittämiseen: stokastista ei-parametrista estimointimenetelmää (Kuosmanen, 2006 ja 2008), stokastista parametrista estimointimenetelmää (mm. Coelli ym., 1998) ja ei-stokastista ei-parametrista DEA -menetelmää (mm. Färe ym., 1994).

\section{Aineisto ja menetelmät}

Tutkimusaineisto koostuu EU:n ylläpitämän FADN -aineiston maitotiloista vuodelta 2003. Erikoistuneiden maitotilojen oletetaan tuottavan yhtä tuotosta, joka koostuu pääasiassa maidosta ja maidontuotannon sivutuotteista. Panoksina ovat perinteiset tuotantopanokset: lannoitteet, ostorehut, työ, muut muuttuvat panokset sekä koneet ja rakennukset. Tuotot ja kustannukset muunnetaan kiinteähintaisiksi maittaisilla indekseillä. Tanskan ja Ruotsin valuutassa ilmaistut panokset muunnetaan euroiksi FADN -aineistossa käytettyjen muuntokertoimien avulla. Tuotteiden ja panosten hintatasoja ei ole korjattu maiden absoluuttisen hintatason erolla. Panosten osalta vastaavaa korjausta ei hinta-aineiston puuttumisen vuoksi ole edes mahdollista tehdä. Sen sijaan tuotteiden absoluuttisia hintoja voitaisiin vertailla. Mikäli maiden hintatasot eroavat toisistaan, hintaerot päätyvät määräeroiksi tuotosten ja panosten määriä kuvaavissa euromääräisissä muuttujissa. Jos hintatasojen ero sekä tuotoksissa että panoksissa on samansuuruinen, se ei vaikuta tuottavuuden tasoeroon, jos toimitaan vakioskaalatuottojen vallitessa. Jos hintatasoerot panosten ja tuotosten osalta poikkeavat kuitenkin toisistaan, se vaikuttaa myös tuottavuuden tasoeroihin. Maakohtaiset tuotos- ja panoskeskiarvot sekä keskihajonnat on esitetty taulukossa 1. Taulukko osoittaa, että sekä erityisesti tanskalaisten mutta myös ruotsalaisten maitotilojen keskikoko on olennaisesti suurempi kuin suomalaisten tilojen.

Taulukko 1. Tutkimustilojen tuotoksen ja panosten keskiarvot ja -hajonnat (std) maittain.

\begin{tabular}{lcccccc}
\hline & \multicolumn{2}{c}{ Tanska } & \multicolumn{2}{c}{ Suomi } & \multicolumn{2}{c}{ Ruotsi } \\
& Keskiarvo & Std & Keskiarvo & Std & Keskiarvo & Std \\
\hline Tuotos $(€)$ & 310134 & 161966 & 83443 & 45964 & 133430 & 133389 \\
Ostorehut $(€)$ & 77346 & 48282 & 18039 & 13336 & 32627 & 38401 \\
Lannoitteet $(€)$ & 5400 & 3561 & 5053 & 3656 & 4363 & 4974 \\
Työ (h) & 4543 & 1630 & 5095 & 1723 & 4461 & 2251 \\
Muut muuttuvat $(€)$ & 96333 & 48662 & 32539 & 17560 & 43250 & 37909 \\
Koneet ja rakennukset $(€)$ & 57988 & 33462 & 23508 & 18200 & 35061 & 37352 \\
\hline
\end{tabular}


Tutkimuksessa sovellettu ensimmäinen menetelmänä on stokastinen ei-parametrinen estimointi $^{1}$, jonka on kehittänyt Kuosmanen (2006, 2008). Aluksi kullekin maalle määritetään oma paloittain lineaarinen tuotantofunktio oheisen mallin mukaan:

$$
\begin{aligned}
& \min _{\alpha \times, i} \sum_{i=1}^{n} \hat{E}_{i}^{2} \\
& \text { s.t. } \\
& y_{i}=\alpha_{i}+\beta_{i}^{\prime} x_{i}+\hat{\varepsilon}_{i} \quad \forall i=1, \ldots, n \\
& y_{h} \leq \alpha_{i}+\beta_{i}^{\prime} x_{h}+\hat{\varepsilon}_{k} \forall h, i=1, \ldots, n \\
& \boldsymbol{\beta}_{\mathbf{i}}^{\prime} \geq 0 \quad \forall i=1, \ldots, n
\end{aligned}
$$

Mallissa stokastisten virhetermien summa minimoidaan rajoittein, jotka sallivat kullekin tilalle omat vakioiden ja rajatuotosten arvot, kuten ensimmäinen rajoite osoittaa. Toinen rajoite pakottaa malliin konkaavisuuden ja kolmas monotonisuuden. Tehottomuus ratkaistaan toisessa vaiheessa momenttimenetelmän avulla. Tällöin edellisen mallin tuloksena saatu virhetermi jaotellaan toisen ja kolmannen keskusmomentin avulla yksipuolisen virhetermin (tehottomuuden) varianssiin ja satunnaisen virhetermin varianssiin (ks. Kumbhakar ja Lovell, 2000). Kun nämä varianssit tiedetään, voidaan käyttää ehdollista estimaattoria tehottomuuden määrittämiseen (Jondrow ym., 1982).

Kun kullekin alueen tilalle on ratkaistu tekninen tehottomuus, lasketaan tehottomuuden keskiarvo, jolla mallin deterministisen osan avulla laskettuja kunkin tilan tuotosestimaatteja korjataan ylöspäin keskimääräisen tehottomuuden osoittaman tuotoksen verran kullakin alueella erikseen. Näin saadaan kullekin tilalle keskimääräisellä maakohtaisella tehottomuudella korjattu tuotoksen määrä. Alueellisesti korjattuihin tuotosestimaatteihin ja tiloilla käytettyihin panoksiin sovelletaan ei-stokastista ei-parametrista verhokäyrämenetelmää (DEA), jolla voidaan puolestaan määrittää tekninen tehottomuus suhteessa yhteiseen tuotantorintamaan, kun keskimääräinen alueellinen tekninen tehottomuus on havainnoista poistettu. Näiden kahden tehottomuusluvun avulla voidaan määrittää maiden väliset tehokkuuserot, jotka kuvaavat näiden maiden maidontuotannon suhteellista tuottavuutta toisiinsa nähden (Battese ym., 2002; O’Donnell ym., 2006).

Toisena menetelmänä sovelletaan tavanomaista DEA -analyysia, koska DEA -mallia voidaan pitää ei-stokastisena erikoistapauksena StoNED -mallista. DEA menetelmälle on ominaista, että DEA meta-rintama verhoaa kaikkia havaintopisteitä. DEA:ta käytettäessä ratkaistaan ensin omat DEA mallit kullekin maalle maakohtaisen teknisen tehottomuuden määrittämiseksi. Tämän lisäksi määritetään kaikille havainnoille yhteinen DEA -malli, joka ilmaisee teknisen tehottomuuden suhteessa yhteiseen meta-rintamaan.

Kolmanneksi kullekin alueelle estimoidaan oma parametrinen stokastinen tuotantorintamafunktionsa, jonka perusteella määritetään maakohtainen tekninen tehottomuus. Yhdistetylle aineistolle ratkaistu tuotantorintamafunktio ei kuitenkaan välttämättä verhoa alueellisia tuotantorintamafunktioita. Sen vuoksi meta-rintama määritetään ohjelmointimallin avulla (Battese ym., 2004). Log-lineaarista (esim. translog) mallia käytettäessä ohjelmointimalli yksinkertaistuu muotoon

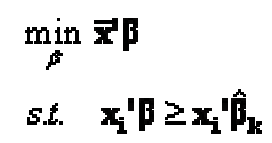

Siten etsitään sellaisia regressiokerrointen $\beta$ arvoja, jotka minimoivat funktion arvon aineiston keskiarvopisteessä siten, että kussakin pisteessä näillä $\beta$ :n arvoilla laskettu tuotos on suurempi tai yhtä suuri kuin alueellisen tuotantofunktion perusteella tilalle estimoitu tuotos.

Kuten edellä todettiin, meta-tuotantorintamatekniikkaa käytettäessä kunkin tilan tuotostehokkuus voidaan määrittää joko poikkeamaksi oman alueen tuotantorintamasta tai poikkeamaksi yhteisestä meta-tuotantorintamasta. Kun meta-tuotantorintama verhoaa kaikkia alueellisia tuotantorintamia,

\footnotetext{
${ }^{1}$ Stochastic nonparametric envelopment of data, jossa käytetään konkaavia ei-parametrista pienimmän neliösumman menetelmää (StoNED; Kuosmanen, 2006 ja 2008).
} 
tuotostehokkuus voidaan jaotella kahdeksi osatekijäksi (MTE eli meta-rintamatehokkuudeksi ja CTE eli maarintamatehokkuudeksi) ja näiden suhdetta kutsutaan meta-teknologia suhteeksi (aiemmin myös teknologiakuiluksi) MTR. Näiden välillä vallitsee seuraava yhteys:

$$
\text { MTE }=\text { CTE } * \text { MTR eli MTR }=\text { MTE } / \text { CTE. }
$$

Neljänneksi edellä esitetyillä tavoilla laskettuja tuottavuuseroja verrataan siihen, millainen tuotosten suhde olisi keskimääräisen ja rintamatuotantofunktion tapauksessa, kun tuotoksen viitetasona käytetään parhaan tuotoksen tuottavaa teknologiaa. Tällöin ei ole tarpeen määrittää erikseen metatuotantorintamaa, vaan alueellisesti määritetyt tuotantofunktion riittävät vertailun tekemiseen. Panostuotosvertailu tehdään laskemalla vuorollaan kunkin maan tuotantoteknologiaa käyttäen jokaisen tilan tuotosestimaatti kyseisen tilan panoskäytön pohjalta. Tässä tapauksessa tuotosestimaatteja on jokaisella tilalla kolme: yksi Tanskan, yksi Suomen ja yksi Ruotsin teknologialla määritettynä.

\section{Tulokset ja tulosten tarkastelu}

Taulukoissa 2 - 4 esitetään keskimääräiset meta- ja maarintamatehokkuudet (MTE ja CTE) sekä metateknologiasuhde (MTR) eri menetelmillä määritettynä. MTE kuvaa, miten teknisesti tehokkaita tilat ovat suhteessa koko aineiston yhteiseen tehokkuusrintamaan. CTE puolestaan kuvaa, miten tehokkaita tilat ovat suhteessa oman alueensa (maansa) tehokkuusrintamaan. MTR kuvaa näiden lukujen suhdetta, eli miten suuri ero on tehokkuusrintamien välillä. Se kuvaa siten myös suhteellista tuottavuuseroa teknologioiden välillä ottaessaan huomioon alueiden mahdolliset sisäiset tehokkuuserot.

Taulukko 2 kuvaa teknistä MTE ja CTE tehokkuutta StoNED -menetelmään perustuen. Maakohtaiset tehokkuudet on määritetty StoNED -estimointia käyttäen, mutta yhteinen metatehokkuusrintama on määritetty maakohtaisilla tehottomuuksilla korjattujen StoNED tuotosestimaattien avulla DEA -menetelmää käyttäen. Tämä perusteella suomalaisten tilojen MTEtehokkuus on selkeästi alhaisin (0.68), mutta CTE-tehokkuus on lähellä Tanskan tasoa ollen kuitenkin hieman alempi (0.90). Siten yhteiseen meta-rintamaan verrattuna tuotosta pitäisi kyetä kasvattamaan yli $30 \%$ :lla, jotta tehokkuusrintama saavutettaisiin, mutta omaan maarintamaan verrattuna tehottomuus on ainoastaan $10 \%$. Ruotsissa maan sisäinen maitotilojen keskimääräinen tekninen tehokkuus on jonkin verran alempi kuin Suomessa ja Tanskassa (0.86), mutta MTE:n ja CTE:n välinen ero on melko pieni. Tämä johtaa siihen, että StoNED -mallin mukaan ruotsalaistilojen tuottavuus suhteessa tanskalaisiin on keskimäärin vain hieman heikompi. Sen sijaan suomalaistilojen MTR on olennaisesti alempi kuin Tanskan ja Ruotsin tiloilla.

Taulukko 2. Tekninen tehokkuus suhteessa meta-rintamaan (MTE), maarintamaan (CTE) sekä metateknologiasuhde (MTR) StoNED -menetelmällä määritettynä.

\begin{tabular}{lrrr}
\hline & MTE & CTE & MTR \\
\hline Tanska & 0.916 & 0.922 & 0.994 \\
Suomi & 0.677 & 0.900 & 0.752 \\
Ruotsi & 0.832 & 0.861 & 0.966 \\
\hline
\end{tabular}

Myös siinä tapauksessa että DEA -menetelmää käytetään sekä maakohtaisen että metarintaman estimointiin, tehokkuusluvut ovat hyvin samankaltaiset (taulukko 3). Koska maakohtaisia tehokkuusrintamia määritettäessä ei oteta huomioon stokastisuutta, maakohtaiset tehokkuuslukujen keskiarvot ovat DEA-estimoinneissa alempia kuin StoNED -mallissa. Myös MTE tehokkuuslukujen arvot ovat keskimäärin selvästi alempia Tanskan ja Ruotsin osalta. Suomen MTE tehokkuusluku on lähes sama. MTEja CTE-lukujen muutoksista seuraa, että Suomen tilojen tuottavuus (MTR) suhteessa Ruotsin ja Tanskan tiloihin on StoNED -mallia jonkin verran parempi. Kuitenkin keskiarvojen suuruusjärjestys on sama molemmilla malleilla. 
Taulukko 3. Tekninen tehokkuus suhteessa meta-rintamaan (MTE), maarintamaan (CTE) sekä metateknologiasuhde (MTR) DEA-menetelmällä määritettynä (muuttuvien skaalatuottojen oletus)..

\begin{tabular}{lrrr}
\hline & MTE & CTE & MTR \\
\hline Tanska & 0.810 & 0.839 & 0.965 \\
Suomi & 0.668 & 0.820 & 0.815 \\
Ruotsi & 0.748 & 0.797 & 0.939 \\
\hline
\end{tabular}

Niin ikään Cobb-Douglas -mallissa (taulukko 4) Suomen maitotilojen tuottavuus (MTR) on heikoin, mutta maan sisäisen tehokkuuden ero Tanskaan verrattuna on pieni kuten edellisissäkin malleissa. Ruotsissa keskimääräinen maakohtainen tehokkuus on selvästi alempi kuin Tanskassa ja Suomessa. Kun yhteinen meta-rintama määritetään kaavan 2 mukaisella ohjelmointimallilla, Suomen ja Ruotsin MTE tehottomuudet tulevat lähes yhtä suuriksi. Koska Ruotsin maakohtainen tehokkuus on Suomea alempi, sen MTR suhde on tässäkin tapauksessa Suomea parempi mutta selkeästi heikompi kuin Tanskan maitotiloilla.

Taulukko 4. Tekninen tehokkuus suhteessa meta-rintamaan (MTE), maarintamaan (CTE) sekä metateknologiasuhde (MTR) Deterministinen ohjelmointimalli meta-rintaman määrittelyssä (tuotantofunktiot Cobb-Douglas -tyyppisiä).

\begin{tabular}{lrrr}
\hline & MTE & CTE & MTR \\
\hline Tanska & 0.767 & 0.894 & 0.858 \\
Suomi & 0.625 & 0.880 & 0.710 \\
Ruotsi & 0.622 & 0.806 & 0.772 \\
\hline
\end{tabular}

Taulukkoon 5 on kerätty meta-teknologiasuhteet, jotka on suhteutettu siten, että Tanskan taso on muunnettu ykköseksi. Näin voidaan verrata, millaisen tuotoksen esimerkiksi suomalaiset tilat ovat keskimäärin saavuttaneet tanskalaisiin tiloihin verrattuna käyttämällään panosmäärällä. Määritettäessä tuottavuus konkaavin verhokäyrän avulla eri menetelmin, suomalaisten tilojen tuottavuus oli menetelmästä riippuen 76 - 84 \% Tanskan tilojen tasosta. Myös Ruotsin tilojen tuottavuuden taso alitti vuonna 2003 Tanskan tilojen tason vaihdellen menetelmän mukaan 90 - 97 \%:n välillä tanskalaisella teknologialla saavutettavasta tuotoksesta. Siten myös Ruotsin tiloilla tuottavuus oli selvästi Suomen tiloja korkeampi.

Teknologiasuhde on hyvin samankaltainen myös silloin, kun verrataan suoraan eri teknologioilla samoin panoksin saavutettuja tuotosestimaatteja joko keskimääräistä tuotantofunktiota tai rintamatuotantofunktiota käyttäen. Ainoa ero näiden välillä on se, että suomalaiset tilat näyttävät rintamatuotantofunktion perusteella pääsevän hieman lähemmäs tanskalaisten tilojen tuottavuuden tasoa kuin keskimääräisen tuotantofunktion perusteella.

Taulukko 5. Tanskaan suhteutettu meta-teknologiasuhde eri menetelmin määritettynä.

\begin{tabular}{lccccc}
\hline & \multicolumn{2}{c}{ Konkaavi verhokäyrä } & \multicolumn{2}{c}{ Tuotantofunktio } \\
& CD & DEA & CNLS & keskim.TF & rintamaTF \\
\hline Tanska & 1.000 & 1.000 & 1.000 & 1.000 & 1.000 \\
Suomi & 0.828 & 0.844 & 0.757 & 0.815 & 0.861 \\
Ruotsi & 0.900 & 0.972 & 0.972 & 0.944 & 0.946 \\
\hline
\end{tabular}

Tanskalainen teknologia dominoi muiden maiden teknologioita eli sen tuottavuus on parempi kuin suomalaisen ja ruotsalaisen teknologian kuten taulukko 6 osoittaa. Kun käytetään Tanskan tilojen panoksia ja keskimääräistä Tanskan Cobb-Douglas tuotantofunktiota, yli 98 \%:ssa tapauksista Tanskan tuotantofunktio tuottaa suurimman tuotoksen. Suomen havaintoja käytettäessä osuus on vajaat 96 \%, ja Ruotsin osalta se on vajaat 88 \%. Tanskalainen teknologia dominoi siten selvästi muiden maiden teknologioita. Jos tuotosestimaatti määritetään rintamatuotantofunktion perusteella, tanskalainen tek- 
nologia dominoi edelleen, mutta ei niin voimakkaasti kuin keskimääräistuotantofunktion tapauksessa (taulukko 7).

Taulukko 6. Suurimman tuotosestimaatin tuottavien teknologioiden osuudet eri tilojen panoskäytöillä maittain (keskimääräinen Cobb-Douglas tuotantofunktio).

\begin{tabular}{lrrr} 
& \multicolumn{3}{c}{ Suurin tuotosestimaatti, \% tiloista } \\
& $\begin{array}{c}\text { Tanskalainen } \\
\text { teknologia }\end{array}$ & $\begin{array}{c}\text { Suomalainen } \\
\text { teknologia }\end{array}$ & $\begin{array}{c}\text { Ruotsalainen } \\
\text { teknologia }\end{array}$ \\
\hline $\begin{array}{l}\text { Tanskalaistilojen } \\
\text { panoskäyttö }\end{array}$ & $98.08 \%$ & $0.27 \%$ & $1.65 \%$ \\
$\begin{array}{l}\text { Suomalaistilojen } \\
\text { panoskäyttö }\end{array}$ & $95.72 \%$ & $3.95 \%$ & $0.33 \%$ \\
$\begin{array}{l}\text { Ruotsalaistilojen } \\
\text { panoskäyttö }\end{array}$ & $87.58 \%$ & $6.54 \%$ & $5.88 \%$ \\
\hline
\end{tabular}

Taulukko 7. Suurimman tuotosestimaatin tuottavien teknologioiden osuudet eri tilojen panoskäytöillä maittain (Cobb-Douglas rintamatuotantofunktio).

\begin{tabular}{|c|c|c|c|}
\hline & $\begin{array}{l}\text { Suurin tu } \\
\text { Tanskalainen } \\
\text { teknologia }\end{array}$ & $\begin{array}{c}\text { otosestimaatti, } \\
\text { Suomalainen } \\
\text { teknologia }\end{array}$ & $\begin{array}{l}\text { \% tiloista } \\
\text { Ruotsalainen } \\
\text { teknologia }\end{array}$ \\
\hline $\begin{array}{l}\text { Tanskalaistilojen } \\
\text { panoskäyttö }\end{array}$ & $86.26 \%$ & $2.75 \%$ & $10.99 \%$ \\
\hline $\begin{array}{l}\text { Suomalaistilojen } \\
\text { panoskäyttö } \\
\text { Ruotsalaistilojen }\end{array}$ & $78.95 \%$ & $12.83 \%$ & $8.22 \%$ \\
\hline panoskäyttö & $62.75 \%$ & $23.86 \%$ & $13.40 \%$ \\
\hline
\end{tabular}

\section{Johtopäätökset}

Tässä tutkimuksessa määritettiin Suomen, Ruotsin ja Tanskan maitotilojen tuottavuuseroja nk. metateknologiasuhdetta hyväksi käyttäen. Vuoden 2003 maitotila-aineistoon sovellettiin useita menetelmiä. Eri menetelmien perusteella tuottavuuserot Tanskan, Suomen ja Ruotsin maitotilojen välillä poikkeavat hieman toisistaan, mutta kaikissa tapauksissa Suomen maitotilat ovat tehottomimpia saavuttaen käyttämillään panoksilla 75 - 85\% Tanskan tilojen tuotoksen tasosta. Tanskan tilojen teknologia on tuottavinta myös valtaosalla panoskombinaatioista. Tästä huolimatta suomalaiset tilat ovat suomalaisiin tiloihin verrattuna jokseenkin yhtä tehokkaita kuten tanskalaiset tanskalaisiin verrattuna. Ruotsalaistilojen keskimääräinen tekninen tehottomuus on suomalaistiloja suurempi.

Vuosien väliset tulokset saattavat poiketa toisistaan mm. säävaihteluiden vuoksi. Sen vuoksi jatkossa on tarpeen tarkastella joko paneeliaineistoa tai ainakin useiden vuosien tuloksia. Tuottavuuseroissa saattaa olla myös systemaattisia muutoksia ajan myötä. Tuottavuuseroja määrittämisen lisäksi jatkossa on tarpeen tutkia, mitkä tekijät tuottavuuseroja aiheuttavat ja mikä on niiden suhteellinen merkitys toisiinsa nähden..

\section{Kirjallisuus}

Battese, G.E.\& Rao. D.S.P. 2002. Technology potential, efficiency and a stochastic metafrontier function. International Journal of Business and Economics 1(2): 1-7.

Battese, G.E., Rao, D.S.P. \& O'Donnell, C.J. 2004. A metafrontier production function for estimation of technical efficiencies and technology gaps for firms operating under different technologies. Journal of Productivity Analysis 21: 91-103.

Coelli, T., Rao, D.S.P. \& Battese, G. 1998. An introduction to efficiency and productivity analysis. Kluwer Academic Publishers. London. 
Färe, R., Grosskopf, S. \& Lovell, C.A.K. 1994. Production frontiers. Kluwer Academic Publishers. London.

Jondrow, J., Lovell C.A.K., Materov I.S. \& Schmidt, P. 1982. On estimation of technical inefficiency in the stochastic frontier production function. Journal of Econometrics 19: 233-238.

O’Donnell, C.J., Rao, D.S.P. \& Battese, G.E. 2006. Meta-frontier frameworks for the study of firmlevel efficiencies and technology ratios. Manuscript.

Kumbhakar, S.C. \& Lovell, C.A.K. 2000. Stochastic frontier analysis. Cambridge University Press. Cambridge.

Kuosmanen, T. 2006. Stochastic nonparametric envelopment of data: Combining virtues of SFA and DEA in unified framework. MTT Discussion Paper 3: $51 \mathrm{s.}$

Kuosmanen, T. 2008. Representation theorem for convex nonparametric least squares. The Econometric Journal (accepted). 